\title{
Effect of Adventitial Dissection of Superficial Temporal Artery on the Outcome of Superficial Temporal Artery- Middle Cerebral Artery Bypass in Moyamoya Disease
}

\author{
Xin $\mathrm{Li}^{1}$, Zheng Huang ${ }^{2}$, Ming-Xing $\mathrm{Wu}^{3}$, Dong Zhang ${ }^{1, * *}$ \\ ${ }^{1}$ Department of Neurosurgery, Beijing Tiantan Hospital, Capital Medical University, Beijing 100050, China \\ ${ }^{2}$ Department of Neurosurgery, Xiangya Hospital, Central South University, Changsha 410008, Hunan, China \\ ${ }^{3}$ Department of Neurosurgery, Beijing Puhua International Hospital, Beijing 100050, China.
}

[Received August 12, 2016; Revised November 14, 2016; Accepted November 15, 2016]

\begin{abstract}
Superficial temporal artery-middle cerebral artery (STA-MCA) has been used for the treatment of occlusive cerebrovascular disease including moyamoya disease. The effect of STA-MCA bypass depends not only on the patency of anastomosis, but also on integrity and functional capacity of the donor artery. In the present prospective study, we investigated the effect of extensive stripping STA adventitia and fasciae on hemodynamic function in STA-MCA bypass of moyamoya disease patients. Twenty patients $(n=8$ in control group, $n=12$ in stripping group) of moyamoya disease were subjected to STA-MCA end-to-side direct anastomosis. Perfusion unit (PU) values of the cortex were measured and recorded using a Laser Doppler flowmetry (LDF) for 5 days. Computed tomography perfusion was performed to determine blood flow before and after bypass. No patient experienced significant neurologic deficits associated with neurosurgical complications. LDF demonstrated that adventitial stripping group had higher cerebral blood flow increase than control group. The adventitia stripping group tends to have higher rate of increased cerebral perfusion after bypass than non-stripping group. Furthermore, the ultrasound examination at 3 days after bypass demonstrated that the adventitial stripping group has a tendency of bigger STA and higher peak systolic velocity than control group. Our result suggests that stripping adventitia of STA improves hemodynamics of STA-MCA bypass in moyamoya disease.
\end{abstract}

Key words: Moyamoya disease, STA-MCA bypass, anastomosis, Laser Doppler Flowmetry, Hemodynamics, cerebral revascularization, adventitia, ischemia

Superficial temporal artery-middle cerebral artery (STAMCA) bypass surgery is a technique that allows low blood flow supply from the extracranial carotid to the distal MCA [1, 2]. STA-MCA bypass procedure has been adopted for the treatment of cerebrovascular occlusive disease and as an adjunct treatment for complex intracranial aneurysms [1]. The key of STA-MCA bypass depends on not only the anastomosis patency but also the blood flow of the donor artery. STA travels within the temporal muscle fascia, thus, its expansion could be affected mechanically by the adventitia and surrounding fascia. In addition, adventitia and fascia of STA contained a large amount of sympathetic nerve fibers [3]. The sympathetic nerve of the artery may play an important role in vascular tone thus affect the blood flow after the STAMCA bypass. We expected that removal of the sympathetic nerve fibers of the STA may promote the artery dilation hence increase blood flow after anastomosis. The present study was to investigate whether stripping of STA adventitia and surrounding fascia has an effect on the bypass patency and regional cerebral blood flow.

*Correspondence should be addressed to: Dong Zhang, M.D., Ph.D. Department of Neurosurgery, Beijing Tiantan Hospital, Capital Medical University, Beijing 100050, China. Email: zhangdong0660@aliyun.com

Copyright: ( $\odot$ 2016. This is an open-access article distributed under the terms of the Creative Commons Attribution License, which permits unrestricted use, distribution, and reproduction in any medium, provided the original author and source are credited. 
Table 1. Patient's information.

\begin{tabular}{|c|c|c|c|c|c|c|c|c|c|c|c|c|}
\hline \multirow{2}{*}{$\begin{array}{c}\text { Age } \\
\text { (years) }\end{array}$} & \multirow[t]{2}{*}{ Sex } & \multirow{2}{*}{$\begin{array}{l}\text { Preop } \\
\text { presentation }\end{array}$} & \multirow{2}{*}{$\begin{array}{l}\text { Surgery } \\
\text { side }\end{array}$} & \multirow[t]{2}{*}{ Stripping } & \multirow[t]{2}{*}{ ICGA } & \multirow[t]{2}{*}{ DSA } & \multirow[t]{2}{*}{ CTA } & \multirow{2}{*}{$\begin{array}{l}\text { Postop } \\
\text { rCBF }\end{array}$} & \multirow{2}{*}{$\begin{array}{l}\text { Postop } \\
\text { result }\end{array}$} & \multicolumn{2}{|c|}{ Follow-up mRS } & \multirow{2}{*}{$\begin{array}{l}\text { Follow-up } \\
\text { cerebrovascular } \\
\text { events }\end{array}$} \\
\hline & & & & & & & & & & Postop & Current & \\
\hline 25 & $\mathrm{~F}$ & SAH & $\mathrm{L}$ & Yes & ++ & ++ & ++ & Improved & Excellent & 0 & 0 & No \\
\hline 40 & M & $\begin{array}{l}\text { Ventricular } \\
\text { hemorrhage }\end{array}$ & $\mathrm{L}$ & Yes & + & & + & Improved & Excellent & 0 & 0 & No \\
\hline 41 & M & $\begin{array}{l}\text { Infarction, } \\
\text { TIA }\end{array}$ & $\mathrm{R}$ & Yes & & + & + & Unchanged & Good & 1 & 1 & Mild headache \\
\hline 45 & $\mathrm{~F}$ & $\begin{array}{l}\text { Infarction, } \\
\text { TIA }\end{array}$ & $\mathrm{L}$ & Yes & & + & + & Improved & Excellent & 2 & 2 & No \\
\hline 46 & $\mathrm{~F}$ & $\begin{array}{l}\text { Infarction, } \\
\text { TIA }\end{array}$ & $\mathrm{L}$ & Yes & & + & + & Improved & Good & 0 & 0 & No \\
\hline 25 & M & $\begin{array}{l}\text { Infarction, } \\
\text { TIA }\end{array}$ & $\mathrm{R}$ & Yes & + & + & + & Improved & Good & 0 & 0 & No \\
\hline 51 & M & TIA & $\mathrm{R}$ & Yes & & + & & Improved & Excellent & 0 & 0 & No \\
\hline 48 & $\mathrm{~F}$ & $\begin{array}{l}\text { Infarction, } \\
\text { TIA }\end{array}$ & $\mathrm{R}$ & Yes & & + & + & Improved & Good & 0 & 0 & Mild headache \\
\hline 52 & $\mathrm{~F}$ & $\begin{array}{l}\text { Infarction, } \\
\text { TIA }\end{array}$ & $\mathrm{R}$ & Yes & + & ++ & ++ & Improved & Good & 0 & 0 & No \\
\hline 42 & $\mathrm{~F}$ & TIA & $\mathrm{L}$ & Yes & & & + & Unchanged & Good & 0 & 1 & $\begin{array}{l}\text { TIA } 3 \text { years } \\
\text { postop }\end{array}$ \\
\hline 41 & $\mathrm{~F}$ & $\begin{array}{l}\text { Infarction, } \\
\text { TIA }\end{array}$ & $\mathrm{L}$ & Yes & + & & + & Unchanged & Excellent & 0 & 0 & No \\
\hline 57 & M & TIA & $\mathrm{L}$ & Yes & ++ & ++ & ++ & Improved & $\begin{array}{l}\text { Excellent, } \\
\text { CHS }\end{array}$ & 0 & 0 & No \\
\hline 43 & M & $\begin{array}{l}\text { Infarction, } \\
\text { TIA }\end{array}$ & $\mathrm{R}$ & No & ++ & ++ & ++ & Improved & Excellent & 1 & 1 & No \\
\hline 29 & $\mathrm{~F}$ & TIA & $\mathrm{L}$ & No & + & ++ & & Unchanged & Good & 0 & 0 & No \\
\hline 22 & M & $\begin{array}{l}\text { Infarction, } \\
\text { TIA }\end{array}$ & $\mathrm{L}$ & No & ++ & + & & Improved & Good & 0 & 0 & No \\
\hline 41 & $\mathrm{~F}$ & $\begin{array}{l}\text { Infarction, } \\
\text { TIA }\end{array}$ & $\mathrm{L}$ & No & + & & + & Unchanged & Excellent & 1 & 1 & No \\
\hline 34 & M & TIA & $\mathrm{L}$ & No & ++ & & ++ & Improved & Excellent & 0 & 0 & No \\
\hline 40 & $\mathrm{~F}$ & $\begin{array}{l}\text { Infarction, } \\
\text { TIA }\end{array}$ & $\mathrm{R}$ & No & + & + & ++ & Improved & Good & 0 & 1 & $\begin{array}{l}\text { TIA } 3 \text { years } \\
\text { postop }\end{array}$ \\
\hline 47 & M & $\begin{array}{l}\text { Infarction, } \\
\text { TIA }\end{array}$ & $\mathrm{R}$ & No & ++ & ++ & ++ & Improved & $\begin{array}{l}\text { Good, } \\
\text { CHS }\end{array}$ & 0 & 0 & No \\
\hline 38 & $\mathrm{~F}$ & $\begin{array}{l}\text { Frontal } \\
\text { hemorrhage } \\
\text { into } \\
\text { ventricles }\end{array}$ & $\mathrm{R}$ & No & & & + & Unchanged & Excellent & 0 & 1 & Mild headache \\
\hline
\end{tabular}

CHS, cerebral hyperperfusion syndrome; CTA, computed tomographic arteriography; DSA, digital subtraction angiography; F, female; ICGA, indocyanine green angiography; $L$, left; $M$, male; $m R S$, modified Rankin Scale; Postop, postoperative; Preop, preoperative; $R$, right; $r C B F$ regional cerebral blood flow; $S A H$, subarachnoid hemorrhage; $S T A-M C A$, superficial temporal artery-middle cerebral artery; TIA, transient ischemic attack; +, patent; ++, highly patent.

\section{MATERILAS AND METHODS}

\section{Patients and clinical features}

Twenty patients of moyamoya disease underwent STAMCA bypass at Beijing Tiantan Hospital from 2012 to 2013 were included in the present study, in which 9 were male and 11 were female (age range, 22 to 58 years; mean age, 41.19 years) (Table 1). The main symptoms were ischemic stroke in 17 and hemorrhagic stroke in 3 patients. All patients were diagnosed of moyamoya disease by digital subtraction angiography (DSA), magnetic resonance imaging (MRI), computed tomography (CT), and computed tomography perfusion (CTP). 


\section{Surgical procedures}

All patients were subjected unilateral or bilateral STAMCA end-side anastomosis under general anesthesia. Before the end-side anastomosis of STA-MCA, the conjunctive and adventitial tissue of STA was dissected. For the adventitial dissection group $(\mathrm{n}=12)$, the length of dissection was 4-5 cm from the distal end of STA. Part of the donor vessel under the bone flap was unfolded to fit the bone flap and the dura to reduce the bending. There were 8 patients in the control group in which adventitial and conjunctive tissue were dissected and removed no more than $1 \mathrm{~cm}$ from distal end of STA [2]. The patency of anastomosis was determined using intraoperative nearinfrared indocyanine green angiography (ICGA).

\section{Perioperative management}

All patients underwent computed tomography angiography (CTA), CTP and/or DSA before and after bypass. The relative change of the perfusion parameter values was evaluated to determine whether $\mathrm{CBF}$ was increased after procedure. All patients were subjected to GE-LOGIQ9 color ultrasound examination using 7L transducer (bandwidth 2.5-7.0 MHz) (GE Healthcare, London, UK) to measure the hemodynamic parameters of the feeding artery before surgery and at 3 days after bypass, including peak systolic velocity (PSV), enddiastolic velocity (EDV), inner diameter (ID), and resistance index (RI).

rCBF was monitored using a LDF (Periflux 5010; Perimed, Beijing, China). Before anastomosis, a LDF probe was placed at different area of the cortex and $\mathrm{rCBF}$ was measured to identify the most severe ischemic area. After anastomosis, the LDF probe was placed to the same site of the cortex and implanted subcutaneously as described previously [4, 5]. The $\mathrm{rCBF}$ was measured before and immediately after STA-MCA bypass, and at 1 , 2, 3, 4, and 5 days after surgery. The LDF probe was pulled out carefully at day 5 after surgery. The rCBF was defined as perfusion unit (PU) value.

The functional outcome assessment was performed using the modified Rankin Scale (mRS) at discharge. The patients were follow-up for transient ischemic attack (TIA), new infarction, and cerebral hemorrhage.

\section{Statistical analysis}

Data are expressed as mean \pm standard deviation and analyzed using independent sample $t$ test with SPSS version 19.0 (SPSS, Chicago, IL). The improvement of PU value from the LDF measurement on the same time point between the two groups was analyzed by two-way ANOVA. The differences in ID, PSV, EDV, and RI from color ultrasound examination before and after the bypass were analyzed by $t$ test. The difference in rCBF from CTP before and after the bypass was compared qualitatively using Chi-square tests. A $p<0.05$ was considered statistically significant.

\section{RESULTS}

\section{Follow-up}

All twenty patients included in the current study had symptoms improvement within the first 2 weeks after surgery. Two patients had transient postoperative headache due to cerebral hyperperfusion syndrome. No other significant neurologic deficit was observed after surgery. All 20 patients were followed up from 59-92 months with a median duration of 66.6 months. No intracranial hemorrhage and infarction were observed during the follow-up. Two patients had TIA at 3 years after surgery. Mild headache occurred in 3 patients. During the follow-up period, mRS maintained at 0 in 12 patients, at 1 to 2 in 4 patients, and improved from 0 to 1 in 2 patients (Table 1).

Table 2. Summary of difference in PU value between the adventitial dissection and control groups.

\begin{tabular}{|c|c|c|c|c|c|c|}
\hline Group & $\begin{array}{c}\text { PU }_{\text {postop- }} \\
\text { PU }_{\text {preop }}\end{array}$ & $\begin{array}{c}\text { PU }_{\text {1d-postop- }} \\
\text { PU }_{\text {preop }} \\
\end{array}$ & $\begin{array}{c}\text { PU }_{\text {2d-postop- }} \\
\text { PU }_{\text {preop }} \\
\end{array}$ & $\begin{array}{c}\text { PU }_{\text {3d-postop- }} \\
\text { PU }_{\text {preop }} \\
\end{array}$ & $\begin{array}{c}\text { PU }_{\text {4d-postop- }} \\
\text { PU }_{\text {preop }} \\
\end{array}$ & $\begin{array}{c}\text { PU }_{\text {5d-postop- }} \\
\text { PU }_{\text {preop }} \\
\end{array}$ \\
\hline Nonstripping (8) & $44.70 \pm 14.92$ & $308.98 \pm 92.20$ & $336.45 \pm 105.79$ & $351.02 \pm 114.83$ & $338.62 \pm 71.73$ & $249.89 \pm 82.04$ \\
\hline Stripping (12) & $42.70 \pm 17.47$ & $479.72 \pm 63.49$ & $447.90 \pm 78.11$ & $543.43 \pm 80.07$ & $457.51 \pm 87.39$ & $536.11 \pm 92.57$ \\
\hline
\end{tabular}



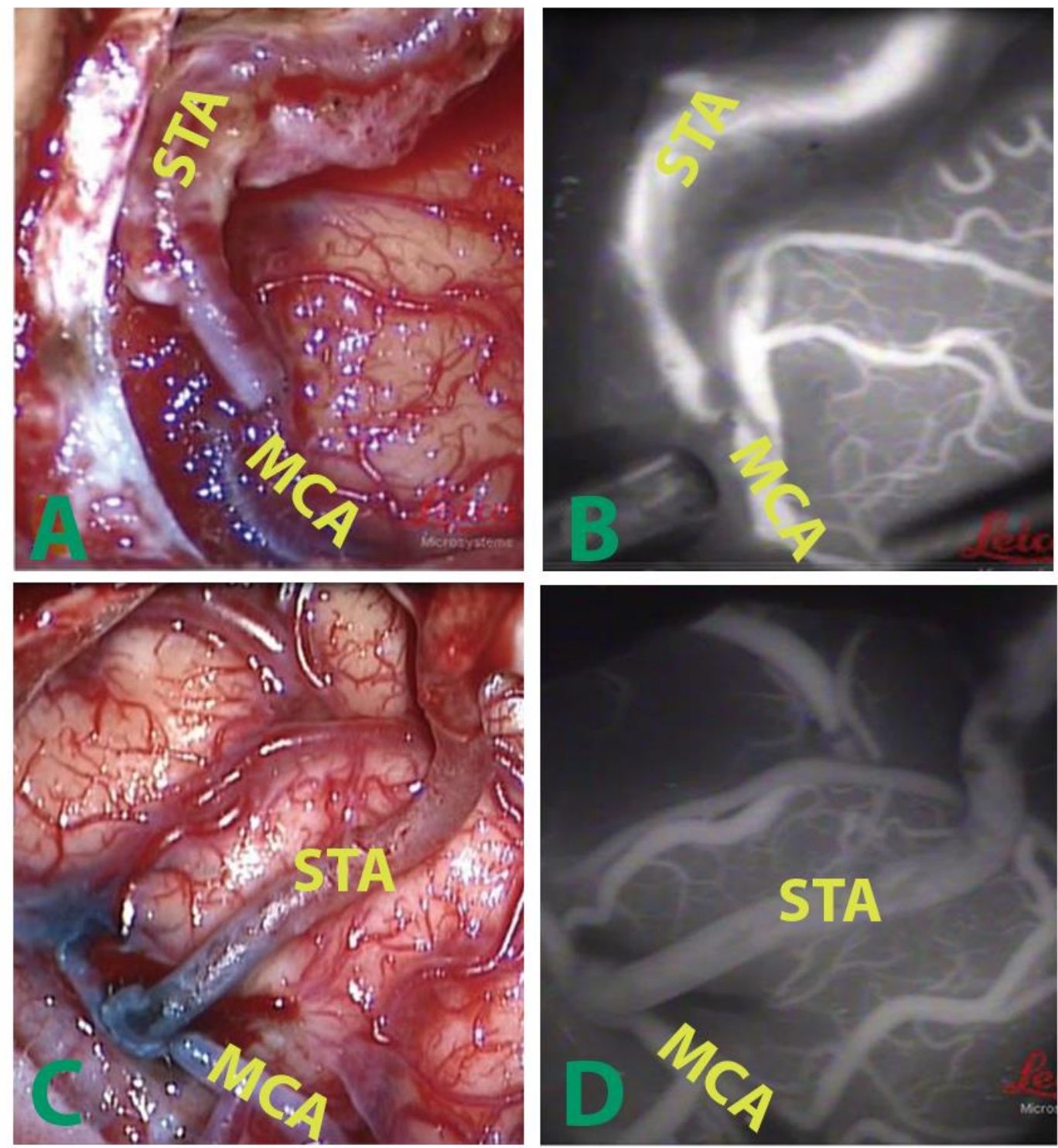

Figure 1. Intraoperative photo and ICGA image in adventitial stripping and control patients. Representative intraoperative photo (A, C) and ICGA image (B, D) of STA-MCA bypass in non-adventitial stripping (A, B) and stripping $(\mathbf{C}, \mathbf{D})$ group. Extensive adventitial and facial stripping was shown in the adventitial stripping group $(\mathbf{C})$ as compared with non-stripping group (A).

\section{Adventitial stripping improved blood perfusion after STA-MCA bypass as compared with non-dissection}

All the 20 patients were subjected ultrasound, DSA and/or CTA to determine patency of the donor artery. Fourteen patients had intraoperative near-infrared ICGA (Fig. 1). CTP were performed in all 20 patients and increase of cerebral perfusion was observed in $62.5 \%(5 / 8)$ and $75 \%$ (9/12) of the control and adventitial stripping group, respectively.

The mean baseline rCBF determined by LDF in the area of anastomosis was $49.30 \pm 19.22$ and $62.61 \pm 27.78$ in the adventitial dissection and control group, respectively $(p=0.220)$. PU values were significantly elevated in both the adventitial stripping and control groups, especially at first day after surgery. Stripping adventitia and facial tissue significant improved the $\mathrm{rCBF}$ (2-way ANOVA, $\mathrm{p}<0.01$ ) (Table 2 and Fig. 2).

We analyzed the change of hemodynamic parameters obtained by ultrasound between the two groups. The improvement of ID, PSV, EDV, and RI was higher in the adventitial stripping group than non-dissection group, although no statistical difference was observed (Table 3). 


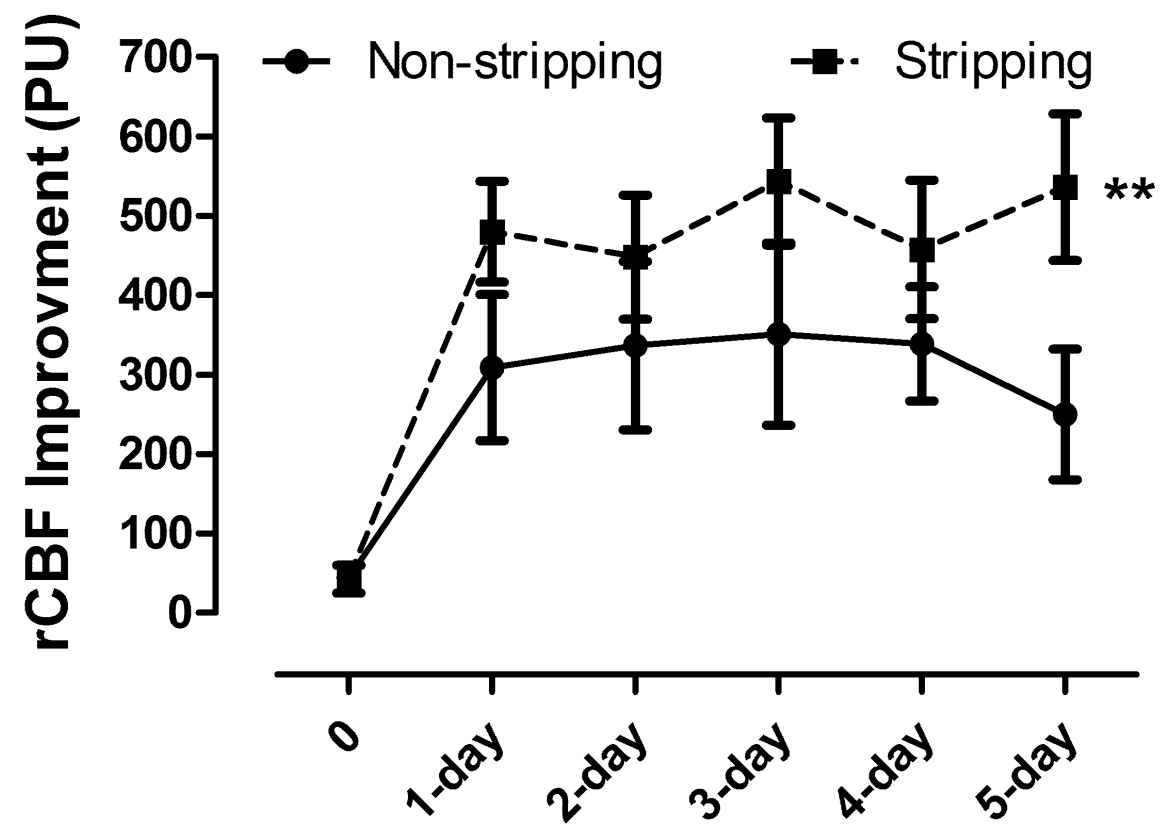

Figure 2. Improvement of rCBF after STA-MCA bypass in non-stripping and stripping group. Significant improvement of $\mathrm{rCBF}$ was indicated in both non-stripping and stripping groups. In addition, stripping adventitia and facial tissue significant improved the rCBF (2-way ANOVA, $p<0.01)$.

\section{DISCUSSION}

STA-MCA bypass allows blood flow bypass proximal lesion of intracranial vasculature and has been used for occlusive cerebrovascular disease for almost half century [6]. In 1980s, STA-MCA bypass fell from favor after an international randomized trial failed to demonstrate any benefit of extracranial-intracranial arterial bypass to reduce the risk of ischemic stroke [7]. In the last two decades, the modern technological advancements such as LDF $[4,5,8]$, infrared camera thermography [8], and quantitative MRA [9] for hemodynamic measurement have allowed us to reappraise the effect of STA-MCA bypasses on cerebrovascular disease $[10,11]$. There is increasing evidence indicated that STA-MCA bypasses not only improve neurological function but also prevent stroke recurrence in subgroup patients of cerebrovascular disease [12-18].

Moyamoya disease is a cerebrovascular disorder characterized by chronic progressive stenosis of intracranial internal carotid arteries and their proximal branches that predisposes the affected patients to stroke. While originally considered exclusive to East Asia, particular in Japan, moyamoya disease has been increasingly diagnosed all over the world with two peaks of age distribution at 5 years and about 40 years [19]. The direct revascularization via STA-MCA anastomosis provides immediate blood supply for the treatment of moyamoya disease. Large-scale case studies have indicated that STA-MCA anastomosis usually has very high bypass patency rate $(>90 \%)[20,21]$. Nonetheless, the improvement of blood flow after STA-MCA bypass has been found inconsistent due to various factors, including age of patients, the length of donor vessel, temporal muscle compression, and graft spasm [22-24] [4] [25] [26, 27].

The success of the revascularization of STA-MCA bypass is greatly depended on the integrity and functional capacity of the donor artery, STA. The cerebrovascular bed is well innervated by both sympathetic and parasympathetic nerve fibers. Although the role of the autonomic nerve system in the regulation of cerebral blood flow remains controversial, it has been indicated that decreasing sympathetic tone may offer therapeutic benefit during cerebral vasospasm [28]. A large amount of sympathetic nerve fibers and nerve endings have been found in STA adventitia and fascia [3, 29]. We speculated that the sympathetic control of STA contributes to the hemodynamic instability after STA-MCA bypass. The present study was to determine the effect of STA denervation on the outcome of STA-MCA bypass in moyamoya disease patients. 
Table 3. Summary of color Doppler hemodynamic parameters between the adventitial dissection and control groups at 3 days after bypass.

\begin{tabular}{|c|c|c|c|c|}
\hline Group & $\begin{array}{l}\text { ID }{ }_{\text {postop- }} \\
\text { ID } \\
\end{array}$ & $\begin{array}{l}\text { PSV }_{\text {postop- }} \\
\text { PSV }_{\text {preop }} \\
\end{array}$ & $\begin{array}{c}\text { EDV }_{\text {postop- }} \\
\text { EDV }_{\text {preop }} \\
\end{array}$ & $\begin{array}{l}\text { RI }_{\text {preop- }} \\
\text { RI }_{\text {postop }} \\
\end{array}$ \\
\hline Nonstripping (8) & $0.338 \pm 0.068$ & $28.63 \pm 6.38$ & $20.76 \pm 3.86$ & $0.1425 \pm 0.1666$ \\
\hline $\begin{array}{c}\text { Stripping (12) } \\
P\end{array}$ & $\begin{array}{c}0.408 \pm 0.083 \\
0.550\end{array}$ & $\begin{array}{c}44.17 \pm 8.39 \\
0.196\end{array}$ & $\begin{array}{c}25.75 \pm 5.76 \\
0.528\end{array}$ & $\begin{array}{c}0.1600 \pm 0.0329 \\
0.641\end{array}$ \\
\hline
\end{tabular}

Values are mean \pm standard deviation. $E D V$, mean of end-diastolic velocity; $I D$, inner diameter; $P S V$, peak systolic velocity; RI, resistance index; postop, value measured after bypass surgery; preop, value measured before bypass surgery.

For STA-MCA bypass, periadventitial tissue layers of STA are normally kept intact with removing conjunctive and adventitial tissues only within $1 \mathrm{~cm}$ of the distal end for anastomosis [30] [2, 31, 32]. In the present study, denervation was achieved by removal adventitia and surrounding fascia at $4-5 \mathrm{~cm}$ of the distal end of STA. Our results demonstrated that stripping adventitial tissues may improve hemodynamic function of STA, evidenced by the increased rCBF measured by LDF. Consistently, the adventitia stripping group tends to have higher rate of increased cerebral perfusion after bypass than nonstripping group. Furthermore, the ultrasound examination at 3 days after bypass demonstrated that the adventitial stripping group has a tendency of bigger STA and higher peak systolic velocity than control group.

Cerebral hyperperfusion syndrome has been well recognized after STA-MCA in moyamoya patients, characterized by ipsilateral throbbing headache, ocular and facial pain, seizure, and focal neurological deficits [33, 34]. In addition, cerebral hyperperfusion has been found to be associated with intracranial hemorrhage after STAMCA bypass [35]. Direct STA-MCA surgery is a lowflow bypass with less possibility of hyperperfusion [27]. Indeed, hypoperfusion, but not hyperperfusion, has been found to be associated with the transient neurological events in moyamoya disease patients after STA-MCA bypass [36]. In the present study, cerebral hyperperfusion syndrome was only observed in 2 patients presented as transient postoperative headache.

In summary, our study has provided the first evidence that stripping the donor artery of adventitia and fascia might improve the hemodynamic function of STAMCA bypass. We expect that the extensive stripping of adventitia and fascia in the donor artery denervates sympathetic control of STA, further inhibits the potential vasospasm after bypass procedure. Our promising result warrants further larger scale clinical study to determine the effect of extensive adventitia and fascia stripping on the long-term outcome of STA-MCA bypass in moyamoya disease patients.

\section{Acknowledgement}

The current study was supported by China National Clinical Research Center for Neurosurgical Diseases (NCRC-ND, 2015BAI12B04), Program of Beijing Municipal Science and Technology Commission (Z13110200680000), and Program of National Natural Science Foundation of China (81371292).

\section{References}

[1] Newell DW (2005). Superficial temporal artery to middle cerebral artery bypass. Skull Base, 15: 133-141

[2] Thines L, Durand A, Penchet G, Proust F, Lenci H, Debailleul A, et al. (2014). Microsurgical neurovascular anastomosis: the example of superficial temporal artery to middle cerebral artery bypass. Technical principles. Neurochirurgie, 60: 158-164

[3] Akiguchi I, Fukuyama H, Kameyama M, Koyama T, Kimura H, Maeda T (1983). Sympathetic nerve terminals in the tunica media of human superficial temporal and middle cerebral arteries: wet histofluorescence. Stroke, 14 62-66

[4] Gesang DZ, Zhang D, Zhao JZ, Wang S, Zhao YL, Wang $\mathrm{R}$, et al. (2009). Laser Doppler flowmeter study on regional cerebral blood flow in early stage after standard superficial temporal artery-middle cerebral artery bypass surgery for moyamoya disease. Chin Med J (Engl), 122: 2412-2418

[5] Gesang D, Zhao JZ, Zhang D, Wang S, Zhao YL, Wang R (2012). [Studying change of regional cerebral blood flow after superficial temporal artery-middle cerebral artery anastomosis during acute stage in patients with Moyamoya disease]. Zhonghua Yi Xue Za Zhi, 92: 20462049

[6] Yasargil MG (1999). A legacy of microneurosurgery: memoirs, lessons, and axioms. Neurosurgery, 45: 10251092

[7] (1985). Failure of extracranial-intracranial arterial bypass to reduce the risk of ischemic stroke. Results of an 
international randomized trial. The EC/IC Bypass Study Group. N Engl J Med, 313: 1191-1200

[8] Kawamata T, Kawashima A, Yamaguchi K, Hori T, Okada Y (2011). Usefulness of intraoperative laser Doppler flowmetry and thermography to predict a risk of postoperative hyperperfusion after superficial temporal artery-middle cerebral artery bypass for moyamoya disease. Neurosurg Rev, 34: 355-362; discussion 362

[9] Zhu FP, Zhang Y, Higurashi M, Xu B, Gu YX, Mao Y, et al. (2014). Haemodynamic analysis of vessel remodelling in STA-MCA bypass for Moyamoya disease and its impact on bypass patency. J Biomech, 47: 1800-1805

[10] Hayden MG, Lee M, Guzman R, Steinberg GK (2009). The evolution of cerebral revascularization surgery. Neurosurg Focus, 26: E17

[11] Wang D, Zhu F, Fung KM, Zhu W, Luo Y, Chu WC, et al. (2015). Predicting Cerebral Hyperperfusion Syndrome Following Superficial Temporal Artery to Middle Cerebral Artery Bypass based on Intraoperative Perfusion-Weighted Magnetic Resonance Imaging. Sci Rep, 5: 14140

[12] Low SW, Teo K, Lwin S, Yeo LL, Paliwal PR, Ahmad A, et al. (2015). Improvement in cerebral hemodynamic parameters and outcomes after superficial temporal artery-middle cerebral artery bypass in patients with severe stenoocclusive disease of the intracranial internal carotid or middle cerebral arteries. J Neurosurg, 123: 662669

[13] Arias EJ, Dunn GP, Washington CW, Derdeyn CP, Chicoine MR, Grubb RL, Jr., et al. (2015). Surgical Revascularization in North American Adults with Moyamoya Phenomenon: Long-Term Angiographic Follow-up. J Stroke Cerebrovasc Dis, 24: 1597-1608

[14] Arikan F, Vilalta J, Torne R, Noguer M, Lorenzo-Bosquet C, Sahuquillo J (2015). Rapid resolution of brain ischemic hypoxia after cerebral revascularization in moyamoya disease. Neurosurgery, 76: 302-312; discussion 312

[15] Serrone JC, Jimenez L, Hanseman DJ, Carroll CP, Grossman AW, Wang L, et al. (2014). Changes in computed tomography perfusion parameters after superficial temporal artery to middle cerebral artery bypass: an analysis of 29 cases. J Neurol Surg B Skull Base, 75: 371-377

[16] Liu XJ, Zhang D, Wang S, Zhao YL, Teo M, Wang R, et al. (2015). Clinical features and long-term outcomes of moyamoya disease: a single-center experience with 528 cases in China. J Neurosurg, 122: 392-399

[17] Muroi C, Khan N, Bellut D, Fujioka M, Yonekawa Y (2011). Extracranial-intracranial bypass in atherosclerotic cerebrovascular disease: report of a single centre experience. Br J Neurosurg, 25: 357-362

[18] Sugiyama T, Kazumata K, Asaoka K, Osanai T, Shimbo D, Uchida K, et al. (2015). Reappraisal of Microsurgical Revascularization for Anterior Circulation Ischemia in Patients with Progressive Stroke. World Neurosurg, 84: 1579-1588

[19] Kuroda S, Houkin K (2008). Moyamoya disease: current concepts and future perspectives. Lancet Neurol, 7: 10561066
[20] Onesti ST, Solomon RA, Quest DO (1989). Cerebral revascularization: a review. Neurosurgery, 25: 618-628; discussion 628-619

[21] Amin-Hanjani S, Du X, Mlinarevich N, Meglio G, Zhao M, Charbel FT (2005). The cut flow index: an intraoperative predictor of the success of extracranialintracranial bypass for occlusive cerebrovascular disease. Neurosurgery, 56: 75-85; discussion 75-85

[22] Sato H, Sato N, Tamaki N, Matsumoto S (1990). Chronic low-perfusion state in children with moyamoya disease following revascularization. Childs Nerv Syst, 6: 166-171

[23] Hirai Y, Fujimoto S, Toyoda K, Inoue T, Uwatoko T, Makihara N, et al. (2005). Superficial temporal artery duplex ultrasonography for improved cerebral hemodynamics after extracranial-intracranial bypass surgery. Cerebrovasc Dis, 20: 463-469

[24] Fujimura M, Kaneta T, Tominaga T (2008). Efficacy of superficial temporal artery-middle cerebral artery anastomosis with routine postoperative cerebral blood flow measurement during the acute stage in childhood moyamoya disease. Childs Nerv Syst, 24: 827-832

[25] Katsuta T, Abe H, Miki K, Inoue T (2015). Reversible occlusion of donor vessel caused by mouth opening after superficial temporal artery-middle cerebral artery anastomosis in adult moyamoya patients. J Neurosurg, 123: $670-675$

[26] Morisawa H, Kawamata T, Kawashima A, Hayashi M, Yamaguchi K, Yoneyama T, et al. (2013). Hemodynamics and changes after STA-MCA anastomosis in moyamoya disease and atherosclerotic cerebrovascular disease measured by micro-Doppler ultrasonography. Neurosurg Rev, 36: 411-419

[27] Yu J, Shi L, Guo Y, Xu B, Xu K (2016). Progress on Complications of Direct Bypass for Moyamoya Disease. Int J Med Sci, 13: 578-587

[28] ter Laan M, van Dijk JM, Elting JW, Staal MJ, Absalom AR (2013). Sympathetic regulation of cerebral blood flow in humans: a review. Br J Anaesth, 111: 361-367

[29] Oka N, Akiguchi I, Matsubayashi K, Kameyama M, Maeda T, Kawamura J (1987). Density of sympathetic nerve terminals in human superficial temporal arteries: potassium permanganate fixation and monoamine oxidase histochemistry. Stroke, 18: 229-233

[30] Newell DW, Vilela MD (2004). Superficial temporal artery to middle cerebral artery bypass. Neurosurgery, 54: 1441-1448; discussion 1448-1449

[31] Nossek E, Langer DJ (2014). How I do it: combined direct (STA-MCA) and indirect (EDAS) EC-IC bypass. Acta Neurochir (Wien), 156: 2079-2084

[32] Charbel FT, Meglio G, Amin-Hanjani S (2005). Superficial temporal artery-to-middle cerebral artery bypass. Neurosurgery, 56: 186-190; discussion 186-190

[33] Piepgras DG, Morgan MK, Sundt TM, Jr., Yanagihara T, Mussman LM (1988). Intracerebral hemorrhage after carotid endarterectomy. J Neurosurg, 68: 532-536

[34] Sundt TM, Jr., Sharbrough FW, Piepgras DG, Kearns TP, Messick JM, Jr., O'Fallon WM (1981). Correlation of cerebral blood flow and electroencephalographic changes during carotid endarterectomy: with results of surgery and 
hemodynamics of cerebral ischemia. Mayo Clin Proc, 56: 533-543

[35] Mao Z, Li M, Li WA, Yu X (2014). Factors associated with delayed intracerebral hemorrhage after superficial temporal artery-middle cerebral artery bypass in stenoocclusive cerebrovascular diseases. Chin Med J (Engl), 127: 633-637

[36] Mukerji N, Cook DJ, Steinberg GK (2015). Is local hypoperfusion the reason for transient neurological deficits after STA-MCA bypass for moyamoya disease? J Neurosurg, 122: 90-94 